\title{
Analysis of the Effect of Dietary Diversity on Anemia in Women of Reproductive Age in Senegal
}

\author{
Jean Augustin Diegane Tine ${ }^{(\mathbb{C}}$, Adama Faye \\ Department of Preventive Medicine and Public Health of the Cheikh Anta Diop University of Dakar (UCAD), Institut de Sante et \\ Developpement (ISED), UCAD, Dakar, Senegal \\ Email: leki105@yahoo.fr, jeanaugustindiegane.tine@ucad.edu.sn
}

How to cite this paper: Tine, J.A.D. and Faye, A. (2019) Analysis of the Effect of Dietary Diversity on Anemia in Women of Reproductive Age in Senegal. Open Journal of Preventive Medicine, 9, 115-125. https://doi.org/10.4236/ojpm.2019.910011

Received: July 26, 2019

Accepted: September 14, 2019

Published: September 17, 2019

Copyright $\odot 2019$ by author(s) and Scientific Research Publishing Inc. This work is licensed under the Creative Commons Attribution International License (CC BY 4.0).

http://creativecommons.org/licenses/by/4.0/

\begin{abstract}
Introduction: Anemia in women of reproductive age is a common health problem in Senegal. The objective of this research was to study the contribution of dietary diversity in the fight against anemia in women of reproductive age in two regions of Senegal using the propensity score method. Methodology: An observational, cross-sectional and analytical study of women of reproductive age and their households was conducted in the Kolda and Kedougou regions in 2015. This was a three-stage random sample survey. The data was collected during an individual interview. Conditional logistic regression was used to identify the risk factor for this anemia. Results: In this study, 1926 women of reproductive age were surveyed. The average age of women of reproductive age surveyed was 27.2 years with a standard deviation of 7.6 years. The median age was 26 years old. Married women were in the majority. Pregnant and lactating women were $43.8 \%$. The percentage of women with adequate diets was $31.5 \%$. The proportion of women with anemia was $51.8 \%$, or 998 women of reproductive age. Adequate dietary diversity is the main factor associated with anemia in these women $(\mathrm{OR}=0.75(0.59-0.96))$. Conclusion: The prevalence of anemia in women of reproductive age is still high in the southern regions of Senegal. To combat this phenomenon, it is therefore necessary to intensify interventions on the balance of diet, iron and folic acid supplementation in pregnant and lactating women and to strengthen the empowerment of women.
\end{abstract}

\section{Keywords}

Anemia, Dietary Diversity, Woman, Senegal

\section{Introduction}

According to WHO, in 2014, an estimated 1.62 billion people worldwide suffer 
from anemia. Children and women of childbearing age are, unfortunately, most at risk, with a global anemia prevalence of $43 \%$ in children under five, $38 \%$ in pregnant women and $29 \%$ in non-pregnant women aged 15 years. at 49 years old. Food consumption has an influence on the occurrence of anemia. The higher a region at a high level of food insecurity, the higher the prevalence of nutritional disorders [1] [2]. In Senegal, according to the EDS-MICS 2010-2011, the prevalence of anemia among women is $54 \%$ against $31 \%$ among men [3].

The health consequences of anemia are multiple. Anemia decreases physical capacity, causes a state of weakness, fatigue, affects the feeling of well-being. It reduces intellectual performance and work capacity thus slowing down productivity. In addition, it reduces the resistance to infections and increases the risk of death during the gravid-puerperal period, resulting in health care costs that could have been avoided. In short, it has major negative consequences for human health and social and economic development [4] [5] [6] [7].

The agriculture and livestock sectors are a priority for the State of Senegal. According to the Ministry of Agriculture and Rural Equipment, cereal production increased by $57 \%$ between 2014 and 2015 [8]. In the Kolda region, production amounted to 5795 tonnes of groundnuts and 105 tonnes of maize seed, 60 tonnes of sorghum seed and 15 tonnes of fonio seed [9]. But despite all these efforts, anemia remains a public health problem more for women and children [3]. The Kolda and Kedougou regions are among the most affected regions. Improving food production does not improve the fight against anemia. To better understand the phenomenon of anemia, we made a hypothesis on the use of food. The hypothesis of this study is that a woman's diet is the main risk factor for the onset of anemia in women of reproductive age. The objective of this study is to analyze the effect of dietary diversity in the fight against anemia in women of childbearing age in southern regions of Senegal using conditional logistic regression with the propensity score matching method on the woman's diet.

\section{Framework of the Study}

This study was conducted in southern Senegal in the Kolda and Kedougou regions. These two regions are among the most disadvantaged regions of Senegal. The Kolda region is composed of three departments: Kolda, Velingara and Medina Yoro Foulah (MYF). The Kedougou region is also composed of three departments: Kedougou, Saraya and Salemata. Figure 1 shows the map of Senegal.

In $2014,16 \%$ of Senegalese households were food insecure, including $2 \%$ in a severe situation and $14 \%$ in a moderate situation. $42 \%$ of households were in a food security situation and $42 \%$ of households were food secure. For the Kolda region, $42 \%$ were moderately or severely food insecure, $40 \%$ were food insecure and $18 \%$ food secure. In Kédougou, 33\% of households were food insecure, $42 \%$ of households were food security limit and $25 \%$ food security [10]. 


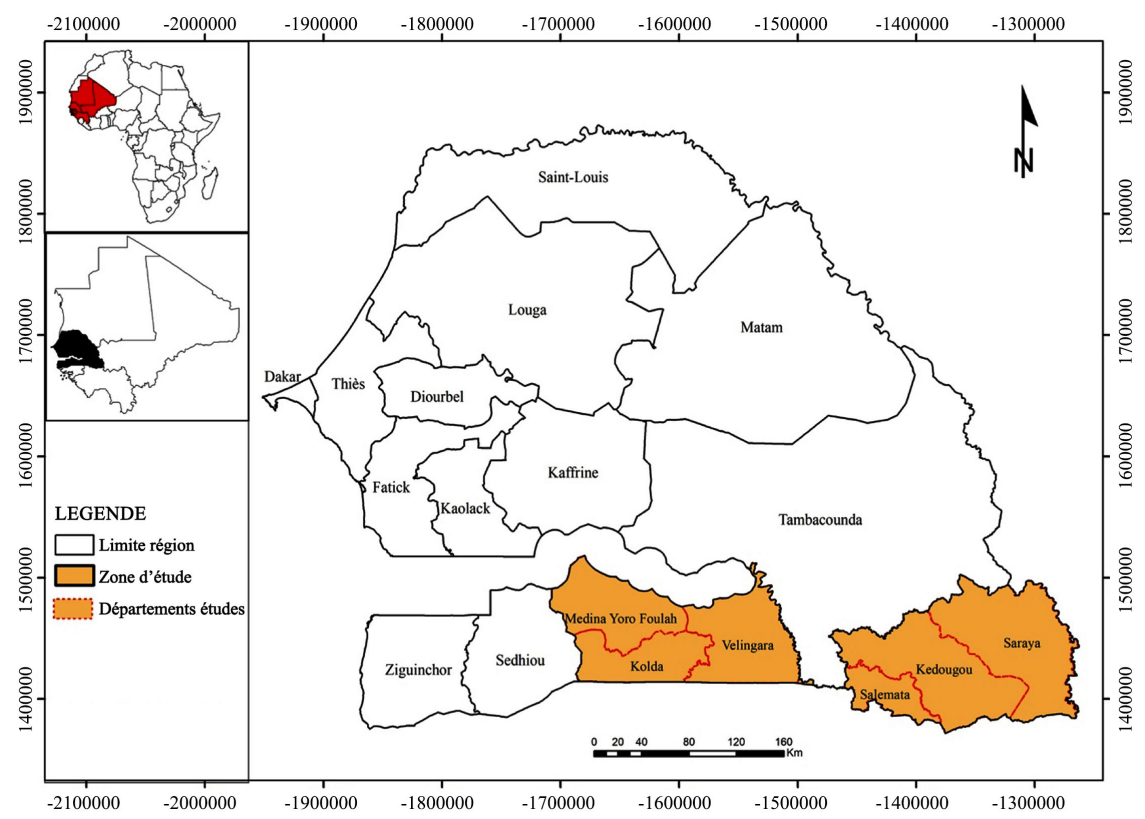

Figure 1. Geographical position of Kolda and Kedougou in Senegal.

In 2013, the percentage of households that practiced agriculture was $79 \%$ in Kolda and $75.5 \%$ in Kedougou. Among them, those who had a stock available in June 2013 were $38.1 \%$ in Kolda and $45.3 \%$ in Kedougou. The practice of breeding was also more frequent in Kolda with $78.2 \%$ of households than in Kedougou with $65.3 \%$ [11].

According to the results by region of EDS-MICS 2010-2011, there is a difficult access to social and health services (only $36.6 \%$ of the population in Kolda and $30.1 \%$ in Kedougou) and the lack of the resources available to supervise the most vulnerable groups, particularly women, are factors contributing to this situation and to the deterioration of the living conditions of the poorest [3].

\section{Materials and Methods}

It is an observational, transversal and analytical study with propensity score matching. It was made between October and December 2015.

This study concerned all women aged between 15 and 45 years in the regions of Kolda and Kedougou and having freely accepted to participate in the study.

The sample size was calculated from the Hsieh formula [12]. It was assessed from a risk $\alpha$ of 5\%, a power of $90 \%$, an anemia prevalence of $54 \%$ and a coefficient $\beta$ expected of 0.2 . With a non-response rate estimated at $10 \%$. The sample size that maximizes the estimates is 1900 households for the six health districts.

A two-stage random survey was conducted. The first degree consisted of the census districts $(\mathrm{CD})$ drawn by villages or neighborhoods and the second degree by households. In total, the study was conducted at the level of sixteen CDs per health district. In each $\mathrm{CD}$, twenty households were selected. At the $\mathrm{CD}$ level, the first grant was drawn, and the others were selected consecutively. A systematic 
draw was made according to the number of households in the CD. In each household a woman was chosen by lottery to be surveyed.

Data collection was based on electronic questionnaires. The investigators were responsible for collecting the data directly on the tablets. They were organized in eighteen teams each of which was guided by a team leader. In each region there was a supervisor. After four days of training, the investigators conducted a pilot survey to test the questionnaires and collectors before starting the actual collection.

Anemia was measured by hemoglobin, which was determined using the $\mathrm{He}-$ moCue@ device. It is a portable haemoglobinometer to quantify the hemoglobin level of the person in less than a minute, from a drop of capillary blood.

As in the EDS-MICS 2010-2011, the woman is considered anemic if the hemoglobin is less than $11 \mathrm{~g} / \mathrm{dl}$. For pregnant women, anemia will be considered mild if the hemoglobin level is between 10.0 and $10.9 \mathrm{~g} / \mathrm{dl}$ [3]. The anemia levels were set at the following intervals [13]:

- Severe anemia $=$ hemoglobinemia $<7 \mathrm{~g} / \mathrm{dl}$,

- Moderate anemia $=7 \mathrm{~g} / \mathrm{dl} \leq$ hemoglobinemia $<10 \mathrm{~g} / \mathrm{dl}$,

- Light anemia $=10 \mathrm{~g} / \mathrm{dl} \leq$ hemoglobinemia $<11 \mathrm{~g} / \mathrm{dl}$.

The CARI Questionnaire from the World Food Program (WFP) assessed the level of food security [14].

The diet has been evaluated through the diversity of foods consumed by the woman. Dietary diversity was appreciated through the number of food groups that women consumed in the 24 hours prior to the survey. In line with the recommendations of the WFP and the Food and Agriculture Organization of the United Nations (FAO) for measuring the Women's Dietary Diversity Score (WDDS), nine food groups were searched. Those who had consumed more than four different food groups a day had a good diet [15]. The woman's diet was considered adequate if the WDDS was four or more.

The data was analyzed with Rsudio. At first, the probability of having an adequate diet was sought. The variables used to construct the propensity score are the main individual characteristics of the woman and the factors related to her household. The propensity scores thus obtained, that is, the conditional probability of having one type of diet, allowed for the match between women in both groups, with a 1:1 ratio. Balance was sought by observing the distribution of these variables between the group having an adequate diet and the group having an inadequate diet. Finally, a conditional logistic regression identified the factors related to anemia in women of reproductive age. Associations were measured by odds ratios (OR) with their confidence intervals.

The approval of the Senegal National Committee for Ethics for Health Research (CNERS) was obtained before the start of field activities. Participation in this study was free. Free and informed consent was obtained from all women aged 18 and over. For women under 18 years of age a consent of their legal guardian was obtained before their own consent. A fact sheet was administered to 
each woman and the legal guardian for minors, before signing the consent form. No compensation was given to the people surveyed. The data collected was confidential. The identity of the individuals who consented to participate was not mentioned on the collection tools. In all uses of the results, anonymity has been respected.

\section{Results}

\subsection{Characteristics of Women and Households}

The average age of women of reproductive age surveyed was 27.2 years with a standard deviation of 7.6 years. The median age was 26 years old. Married women were in the majority. Pregnant and lactating women accounted for $43.8 \%$. The percentage of women with adequate diets was $31.5 \%$. The proportion of women with anemia was $51.8 \%$, or 998 women of reproductive age.

Most households had between seven and twelve people (39.9\%). Poor households were the majority at $34 \%$. The majority of the households surveyed lived in rural areas (76.2\%). Of all the households surveyed, 50.3\% were from the Kolda region. Households with food insecurity were $36.3 \%$.

Before matching, the distribution of the variables between the group of women with an adequate diet and those with an inadequate diet shows an imbalance. Indeed, on several characteristics, we have statistically significant differences between the two groups of the diet (as shown in Table 1).

After pairing by propensity score construction, it shows a perfect balance between the adequate diet group and the inadequate diet group. Matching with a 0.02 caliper resulted in two groups of 536 matched women. No difference is statistically significant (as shown in Table 2). The biggest difference is noted for the income-generating activity ( $34.1 \%$ vs. $29.9 \%$ ).

\subsection{Risk Factors Associated with Anemia in Women of Reproductive Age in Kolda}

The conditional logistic regression made with the paired base allowed to have an explanatory model with all the adjustment variables (logistic model 1). The stepwise method allowed for the most parsimonious model (logistic model 2). Thus, the factors associated with anemia of the woman found are the adequate $\operatorname{diet}(\mathrm{OR}=0.75(0.59-0.96))$, pregnancy or breastfeeding $(\mathrm{OR}=1.69(1.31$ $2.17)$ ). Women living in the Kolda region are less exposed to anemia than women in the Kedougou region. Table 3 shows the two models of conditional logistic regression of anemia among women of reproductive age.

\section{Discussion}

This study allowed us to estimate the prevalence of anemia of women in Kolda and Kedougou regions through the use of hemoglobinometers. The proportion of women with anemia was $51.8 \%$, or 998 women of reproductive age. According to the ongoing EDS 2010-2011, in Senegal, the prevalence of anemia among 
women is $54 \%$, of which $61 \%$ among pregnant women $49 \%$ among those who are breastfeeding [3]. In Guinea Conakry globally $49 \%$ of women suffer from anemia. In Côte d'Ivoire, the EDS-MICS 2011-2012, recorded 54\% of anemic women [16].

Indeed, the Vitamin and Mineral Nutrition Information System (VMNIS) classifies the prevalence of anemia greater than or equal to $40 \%$ as severe [17].

This study found women who had an adequate diet were women who ate at least four food groups a day. These women were less likely to be anemic than women who had a poor diet with an odds ratio of 0.75 with a confidence interval between 0.59 and 0.96 .

The inadequate dietary diversity is an important risk factors for anemia in women of reproductive age in southern Senegal.

Table 1. Characteristics of women and households according to diet before matching.

\begin{tabular}{|c|c|c|c|}
\hline \multirow[t]{2}{*}{ Characteristics } & $\begin{array}{l}\text { Adequate diet } \\
\qquad(\mathrm{N}=606)\end{array}$ & $\begin{array}{l}\text { Inadequate diet } \\
\qquad(\mathrm{N}=1320)\end{array}$ & \multirow[t]{2}{*}{$P$ value } \\
\hline & $\mathrm{n}(\%)$ & $\mathrm{n}(\%)$ & \\
\hline \multicolumn{4}{|c|}{ Women characteristics } \\
\hline $\begin{array}{l}\text { Instruction } \\
\text { (Yes VS. No) }\end{array}$ & $231(38.1)$ & $346(26.2)$ & $<0.001$ \\
\hline $\begin{array}{l}\text { Maternal situation of women } \\
\text { (Pregnant or lactating VS. } \\
\text { Not pregnant or not lactating) }\end{array}$ & $261(43.1)$ & $582(44.1)$ & 0.711 \\
\hline $\begin{array}{l}\text { Income generating activity of women } \\
\text { (Yes VS. No) }\end{array}$ & $208(34.3)$ & $305(23.1)$ & $<0.001$ \\
\hline $\begin{array}{l}\text { Folic acid iron supplementation } \\
\text { (Yes VS. No) }\end{array}$ & $568(93.7)$ & $1215(92.0)$ & 0.224 \\
\hline $\begin{array}{c}\text { Micronutrient supplementation } \\
\text { (Yes VS. No) }\end{array}$ & $103(17.0)$ & $247(18.7)$ & 0.399 \\
\hline \multicolumn{4}{|c|}{ Households characteristics } \\
\hline $\begin{array}{l}\text { Marital status of the household } \\
\text { (Married VS. Not married) }\end{array}$ & $589(97.2)$ & $1286(97.4)$ & 0.890 \\
\hline $\begin{array}{l}\text { Geographical area } \\
\text { (Urban VS. Rural) }\end{array}$ & $167(27.6)$ & $272(20.6)$ & 0.001 \\
\hline $\begin{array}{c}\text { Region } \\
\text { (Kolda VS. Kedougou) }\end{array}$ & $349(57.6)$ & $619(46.9)$ & $<0.001$ \\
\hline $\begin{array}{c}\text { Economic situation of the household } \\
\text { ( } \leq \text { Poverty threshold VS. }>\text { poverty threshold) }\end{array}$ & $268(44.2)$ & $910(68.9)$ & $<0.001$ \\
\hline $\begin{array}{c}\text { Household size } \\
(\leq 12 \text { people VS. }>12 \text { people })\end{array}$ & $324(53.5)$ & $887(67.2)$ & $<0.001$ \\
\hline $\begin{array}{l}\text { Household food security } \\
\text { (Security VS. Insecurity) }\end{array}$ & $479(79.0)$ & $747(56.6)$ & $<0.001$ \\
\hline Propensity score & $0.38 \pm 0.15$ & $0.28 \pm 0.14$ & $<0.001$ \\
\hline
\end{tabular}


Table 2. Characteristics of women and households according to diet after matching.

\begin{tabular}{|c|c|c|c|}
\hline \multirow{2}{*}{ Characteristics } & Adequate diet $(\mathrm{N}=536)$ & Inadequate diet $(\mathrm{N}=536)$ & \multirow{2}{*}{$P$ value } \\
\hline & n (\%) & $\mathrm{n}(\%)$ & \\
\hline \multicolumn{4}{|c|}{ Women characteristics } \\
\hline $\begin{array}{l}\text { Instruction } \\
\text { (Yes VS. No) }\end{array}$ & $179(33.4)$ & $191(35.6)$ & 0.480 \\
\hline $\begin{array}{l}\text { Maternal situation of women } \\
\text { (Pregnant or lactating VS. } \\
\text { Not pregnant or not lactating) }\end{array}$ & $229(42.7)$ & $223(41.6)$ & 0.757 \\
\hline $\begin{array}{l}\text { Income generating activity of women } \\
\text { (Yes VS. No) }\end{array}$ & $160(29.9)$ & $183(34.1)$ & 0.150 \\
\hline $\begin{array}{l}\text { Folic acid iron supplementation } \\
\text { (Yes VS. No) }\end{array}$ & $501(93.5)$ & $502(93.7)$ & 1.000 \\
\hline $\begin{array}{l}\text { Micronutrient supplementation } \\
\text { (Yes VS. No) }\end{array}$ & $97(18.1)$ & $112(20.9)$ & 0.280 \\
\hline \multicolumn{4}{|c|}{ Households characteristics } \\
\hline $\begin{array}{l}\text { Marital status of the household } \\
\text { (Married VS. Not married) }\end{array}$ & $522(97.4)$ & $521(97.2)$ & 1.000 \\
\hline $\begin{array}{l}\text { Geographical area } \\
\text { (Urban VS. Rural) }\end{array}$ & $148(27.6)$ & $149(27.8)$ & 1.000 \\
\hline $\begin{array}{c}\text { Region } \\
\text { (Kolda VS. Kedougou) }\end{array}$ & $310(57.8)$ & $315(58.8)$ & 0.804 \\
\hline $\begin{array}{c}\text { Economic situation of the household } \\
(\leq \text { Poverty threshold VS. }>\text { poverty threshold })\end{array}$ & $262(48.9)$ & $266(49.6)$ & 0.855 \\
\hline $\begin{array}{c}\text { Household size } \\
(\leq 12 \text { people VS. }>12 \text { people })\end{array}$ & $295(55.0)$ & $302(56.3)$ & 0.712 \\
\hline $\begin{array}{l}\text { Household food security } \\
\text { (Security VS. Insecurity) }\end{array}$ & $410(76.5)$ & $403(75.2)$ & 0.669 \\
\hline Propensity score & $0.36 \pm 0.13$ & $0.36 \pm 0.13$ & $>0.999$ \\
\hline
\end{tabular}

Table 3. Factors associated with anemia in women of reproductive age (by conditional logistic regression).

\begin{tabular}{|c|c|c|c|c|c|}
\hline \multirow{2}{*}{ Covariates } & \multirow{2}{*}{$\begin{array}{c}\text { Univariate } \\
\text { Crude OR }(95 \% \mathrm{CI})\end{array}$} & \multicolumn{2}{|c|}{ Logistic model 1} & \multicolumn{2}{|c|}{ Logistic model 2} \\
\hline & & Adj OR (95\% CI) & pvalue & Adj OR (95\% CI) & $P$ value \\
\hline \multicolumn{6}{|c|}{ Women characteristics } \\
\hline $\begin{array}{l}\text { Woman's diet } \\
\text { (adequate VS. inadequate) }\end{array}$ & $0.74(0.58-0.95)$ & $0.75(0.59-0.96)$ & 0.023 & $0.75(0.59-0.96)$ & 0.022 \\
\hline $\begin{array}{l}\text { Instruction } \\
\text { (Yes VS. No) }\end{array}$ & $0.77(0.6-0.99)$ & $0.82(0.63-1.07)$ & 0.142 & $0.82(0.63-1.06)$ & 0.137 \\
\hline $\begin{array}{l}\text { Maternal situation of women } \\
\text { (Pregnant or lactating VS. } \\
\text { Not pregnant or not lactating) }\end{array}$ & $1.73(1.36-2.22)$ & $1.7(1.32-2.19)$ & $<0.001$ & $1.69(1.31-2.17)$ & $<0.001$ \\
\hline $\begin{array}{c}\text { Income generating activity of women } \\
\text { (Yes VS. No) }\end{array}$ & $0.73(0.56-0.94)$ & $0.78(0.6-1.03)$ & 0.075 & $0.78(0.6-1.02)$ & 0.07 \\
\hline $\begin{array}{l}\text { Folic acid iron supplementation } \\
\text { (Yes VS. No) }\end{array}$ & $0.67(0.41-1.11)$ & $0.69(0.41-1.16)$ & 0.163 & & \\
\hline $\begin{array}{l}\text { Micronutrient supplementation } \\
\text { (Yes VS. No) }\end{array}$ & $0.84(0.62-1.14)$ & $0.83(0.61-1.14)$ & 0.256 & & \\
\hline
\end{tabular}




\section{Continued}

\begin{tabular}{|c|c|c|c|c|c|}
\hline \multicolumn{6}{|c|}{ Households characteristics } \\
\hline $\begin{array}{c}\text { Region } \\
\text { (Kolda VS. Kedougou) }\end{array}$ & $1.56(1.22-1.99)$ & $1.54(1.19,2)$ & 0.001 & $1.55(1.2-2)$ & $<0.001$ \\
\hline $\begin{array}{l}\text { Geographical area } \\
\text { (Urban VS. Rural) }\end{array}$ & $0.77(0.59-1)$ & $0.78(0.59-1.04)$ & 0.088 & $0.79(0.59-1.04)$ & 0.097 \\
\hline $\begin{array}{c}\text { Economic situation of the household } \\
\text { ( } \leq \text { poverty threshold VS. > poverty threshold) }\end{array}$ & $1.01(0.79-1.28)$ & $1.19(0.91-1.56)$ & 0.192 & $1.2(0.93-1.55)$ & 0.15 \\
\hline $\begin{array}{c}\text { Household size } \\
(\leq 12 \text { people VS. }>12 \text { people })\end{array}$ & $0.91(0.72-1.16)$ & $1.06(0.81-1.39)$ & 0.66 & & \\
\hline $\begin{array}{l}\text { Household food security } \\
\text { (Security VS. Insecurity) }\end{array}$ & $0.84(0.63-1.11)$ & $0.88(0.66-1.18)$ & 0.39 & & \\
\hline $\begin{array}{l}\text { Marital status of the household } \\
\text { (Married VS. Not married) }\end{array}$ & $1.45(0.68-3.06)$ & $1.45(0.67-3.12)$ & 0.348 & & \\
\hline
\end{tabular}

Most anemic women are pregnant or breastfeeding. Our study showed that the risk of anemia is multiplied by 1.69 in pregnant or lactating women. EDS-MICS 2010-2011 states that Senegalese pregnant women are more often anemic $(61 \%)$ than those who are breastfeeding $(49 \%)$ or those who are neither pregnant nor breastfeeding (56\%) [3]. According to the Bayébié study, $66.1 \%$ of pregnant women in the Dakar region have anemia [18]. WHO estimated in 2015 worldwide that $43 \%$ of pregnant women were anemic compared to $33 \%$ of non-pregnant women [19]. Leke and Kremp noted that in Africa, $66.6 \%$ of pregnant women were anemic [20]. Miguel found that in Costa Rica, $60 \%$ of pregnant women are anemic [21]. The prevalence of anemia was twice as high among pregnant women as among other women [22].

This high prevalence of anemia in pregnant or breastfeeding women may have several explanations: the iron and folic acid deficiency deficit, the needs of which are increased with a diet that is not very diversified, the low rate of women's participation in prenatal consultation and supplementation programs, the lack of access to health facilities and the low decision-making power of women. Khadim et al have shown that among pregnant women who are on iron and folic acid supplementation, only $56 \%$ are adherent to iron and folic acid for 90 days. The level of education and accessibility of prenatal consultation services were key determinants of iron and folic acid intake [23]. A good level of education of the woman would also protect against the occurrence of anemia in women. In Côte d'Ivoire, anemia is more common among women with no education (55.3\%) than among those with primary (54.3\%) and secondary (48.8\%) [16].

This study showed that women with an income-generating activity (IGA) have fewer cases of anemia than those without an IGA. The income generating activity seems to protect against anemia. The financial autonomy of women increases their decision-making power over their medical follow-up.

Anorlu had found in Nigeria that socio-economic status was significantly associated with anemia $(\mathrm{p}<0.001)$ with higher prevalence among women of low 
socioeconomic status [24]. The survey in Mauritania revealed that the percentage of anemic subjects is slightly higher among women who do not work (50.2\%) than among women who work (46.8\%) [25]. In 2013, Bayébié found in Dakar that economic activity reduced the risk of anemia [18]. A good level of socio-economic well-being is a protective factor against anemia. According to EDS 2010-2011, the prevalence of anemia is $58 \%$ for women in the poorest households against 53\% for those of the richest households [3].

Food diversity and anemia are therefore a health problem related to the socio-economic level of the countries. A good socio-economic level would be a protective factor against anemia through a better nutritional status [26] [27] [28].

The implementation of food fortification and diversification strategies is necessary to successfully cover the micronutrient intake of vulnerable populations.

\section{Conclusions}

Anemia is the most common abnormality in hematology. It is a major public health problem particularly in developing countries and frequently affects women of reproductive age. The proportion of women with anemia was $51.8 \%$, or 998 women. The study showed that a good diet in women could protect against anemia especially during pregnancy and breastfeeding.

Interventions integrating food diversification and economic development must be implemented in Senegal at all levels of the health pyramid to combat anemia among women.

\section{Acknowledgements}

- Centre d'Excellence Africain pour la Santé de la Mère et de l'Enfant (CEASAMEF/UCAD).

- All women who agreed to participate in this survey.

\section{Conflicts of Interest}

The authors declare no conflicts of interest regarding the publication of this paper.

\section{References}

[1] Branca, F., Mahya, L. and Shireen Mustafa, T. (2014) The Lack of Progress in Reducing Anemia between Women: The Inconvenient Truth. Bulletin of the World Health Organization, 92, 231. https://doi.org/10.2471/BLT.14.137810

[2] Stevens, G.A., Finucane, M.M., De-Regil, L.M., Paciorek, C.J., Flaxman, S.R., Branca, F., et al. (2013) Global, Regional, and National Trends in Hemoglobin Concentration and Prevalence of Total and Severe Anemia in Children and Pregnant Women and Non-Pregnant Women for 1995-2011: A Systematic Analysis of Population-Representative Data. The Lancet Global Health, 1, e16-e25. https://doi.org/10.1016/S2214-109X(13)70001-9

[3] National Agency of Statistics and Demography (ANSD) of Senegal (2012) Demo- 
graphic and Health Survey with Multiple Indicators 2010-2011. Final Report (EDS-MICS 2010-2011). Dakar.

http://www.ansd.sn/ressources/rapports/EDS-MICS 2010-11 Rapport final.pdf

[4] WHO, UNICEF, UNFPA and the World Bank (2007) Maternal Mortality in 2005. Geneva, 16-18.

[5] Leslie, J. (1991) Women's Nutrition: The Key to Improving Family Nutrition in Developing Countries? Health Policy and Planning, 6, 1-19. https://doi.org/10.1093/heapol/6.1.1

[6] Lemonnitv, D. and Ingenblwk, C.I.Y. (1989) Nutritional Deficiencies in Developing Countries. Third Day of the Girm. KARTHALA, ACCT, Paris, 280-284.

[7] Ayoubi, J.M., Hirt, R., Badiou, W., Hininger-Favier, I., Zraik-Ayoubi, F., Berrebi, A. and Pons, J.C. (2012) Nutrition and Pregnant Woman. EMC Obstetric Gynecology, 5-7. https://doi.org/10.1016/S0246-0335(12)70039-X

[8] MAER (2013) Report Presenting the Final Results of the 2012-2013 Survey. Senegal. https://www.au-senegal.com/IMG/pdf/rapport de pre sentation des re sultats de finitifs de la campagne agrico

[9] Multinational Program for Strengthening Resilience to Food and Nutrition Insecurity in the Sahel (P2RS) (2017) Terms of Reference for the Second Session of the National Steering Committee of the Multinational Program for Strengthening Resilience to Food and Nutrition Insecurity in the Sahel. Ministry of Agriculture and Rural Equipment, Senegal.

[10] SECNA, WFP, UNICEF (2014) Global Analysis of Vulnerability, Food Security and Nutrition (AGVSAN). Senegal. https://documents.wfp.org/stellent/groups/public/documents/ena/wfp266798.pdf

[11] SECNSA, SAP (2013) National Survey on Food Security and Nutrition (ESAN). WFP, Senegal. http://anads.ansd.sn/index.php/catalog/22

[12] Hsieh, F.Y., Bloch, D.A. and Larsen, M.D. (1998) A Simpler Method of Sample Size Calculation for Linear and Logistic Regression. Statistics in Medicine, 17, 1623-1634.

https://doi.org/10.1002/(SICI)1097-0258(19980730)17:14<1623::AID-SIM871>3.0.C $\underline{\mathrm{O} ; 2-\mathrm{S}}$

https://pdfs.semanticscholar.org/7603/e3b38c6dc1965843a76f10b6af330a919dcf.pdf

[13] DeMaeyer, M. (1989) Preventing and Controlling Iron Deficiency Anemia through Primary Health Care: A Guide for Health Administrators and Program Managers. Geneva.

[14] Food Security Analysis Service (VAM) (2014) Consolidated Approach of the World Food Program (WFP) for the Reporting of Food Security Indicators (CARI). WFP, Rome. https://resources.vam.wfp.org/sites/default/files/CARI Final 0.pdf

[15] FAO (2004) Workshop on Dietary Diversity and Dietary Quality. WHO, IFPRI, Geneva, 11-13.

[16] Ministry of Health and AIDS Control (2013) Demographic and Health Survey and Multiple Indicators-Côte d'Ivoire (EDS-MICS), 2011-2012. Final Report, 202-203.

[17] Benoist, B., et al. (2008) Worldwide Prevalence of Anemia 1993-2005. WHO Global Database on Anemia. World Health Organization, Geneva. http://apps.who.int/iris/bitstream/10665/43894/1/9789241596657 eng.pdf

[18] Bayebié, B. (2013) Analysis of Socioeconomic Determinants of Iron Deficiency Anemia in Pregnant Women in Senegal: Case of the Dakar Region 2013 [Memory]. Health Economics, Dakar. 
[19] Branca, F., Mahy, L. and Mustafa, T.S. (2014) The Lack of Progress in Reducing Anemia among Women: The Inconvenient Truth. Bulletin of the World Health Organization, 92, 231. https://doi.org/10.2471/BLT.14.137810

[20] Leke, L. and Kremp, D. (1989) Impact of Nutritional Deficiencies on Anemia in Pregnant Women. Développement et Santé, No. 84, 4-6.

[21] Miguel-Flores, M.D. (1990) The Pregnant Woman and Anemia. In: Mothers and Children, Maternal Nutrition, Vol. 9.

[22] Tine, S.C. (2011) Aggregation Factors for Household Anemia in Cameroon 2011 [Nutrition Brief]: Montreal. 178 p.

[23] Niang, K., Faye, A., Tine, J.A.D., Diongue, F.B., Ndiaye, B., Ndiaye, M.B., Ndiaye, P. and Tal-Dia, A. (2017) Determinants of Iron Consumption among Pregnant Women in Southern Senegal. Open Journal of Obstetrics and Gynecology, 7, 41-50. https://doi.org/10.4236/ojog.2017.71005

[24] Anorlu, R.I., Oluwole, A.A. and Abudu, O.O. (2006) Sociodemographic Factors in Anemia in Pregnancy at Booking in Lagos, Nigeria. Journal of Obstetrics and Gynaecology, 26, 773-776. https://doi.org/10.1080/01443610600963846

[25] Sheikh, M., El Hafed, O., Benzerroug, A., Isselmou, O., et al. (2001) Anemia in Women of Reproductive Age Wilaya du Gorgol (Mauritania). WHO Support. 23 p.

[26] Guiro, A.T. (1991) Iron Deficiency in Senegal: Interest of the Study of the Bioavailability of Dietary Iron in the Estimation of the Coverage of Iron Needs. Thesis, Medicine University, Paris, $291 \mathrm{p}$.

[27] Berger, J. (2004) Food Fortification in Micronutrients: Part of an Integrated Strategy to Combat Micronutrient Deficiencies, Particularly in Iron, in Developing Countries. University Presses of Ouagadougou, IRD, Paris, 563-575.

[28] Berger, J. and Dillon, J.C. (2002) Strategies for Controlling Iron Deficiency in Developing Countries. French Studies and Research Papers/ Health, 12, 22-30. 